\title{
Kajian Sosial Ekonomi Sengketa Lingkungan Berbasis Ekosistem
}

\author{
Widya Andharie Rahasthera ${ }^{1 *}$ \\ ${ }^{1}$ ECOTAS, Cigadung Green Land A9, Bandung 40191 INDONESIA
}

\author{
Kata Kunci: \\ sosial ekonomi, \\ sengketa lingkungan, \\ berbasis ekosistem
}

\begin{abstract}
Abstrak
Penurunan kualitas lingkungan seringkali berkaitan dengan keluhan masyarakat terhadap dampak penurunan kualitas tersebut. Dampak penurunan kualitas lingkungan yang menyebabkan pengaruh terhadap kehidupan sosial ekonomi masyarakat tidak jarang menimbulkan konflik. Artikel ini bertujuan untuk menjelaskan konsep pendekatan ekosistem sebagai bagian dari analisis konflik lingkungan yang lebih komprehensif dan holistik. Analisis dan pemetaan pemangku kepentingan dalam pendekatan ekosistem merupakan salah satu bagian penting dalam pemetaan konflik aspek sosial ekonomi untuk mendapatkan gambaran yang utuh sehingga dapat membantu upaya penyelesaian konflik lingkungan dengan memperhatikan konteks lokal.

\section{Abstract}

The decline in environmental quality is often related to public complaints about the impact of the decline in quality. The impact of environmental degradation that causes an influence on the socio-economic life of the community often causes conflict. This article aims to explain the concept of an ecosystem approach as part of a more comprehensive and holistic analysis of environmental conflicts. Analysis and mapping of stakeholders in the ecosystem approach is an important part of mapping conflict in the socio-economic aspects to get a complete picture so that it can help efforts to resolve the conflicts by taking into account the local context.
\end{abstract}

Keywords: social economic, environmental dispute, ecosystem based

\section{1}

\section{PENDAHULUAN}

Penurunan kualitas lingkungan seringkali berkaitan dengan keluhan masyarakat terhadap dampak penurunan kualitas tersebut. Dampak penurunan kualitas lingkungan yang menyebabkan pengaruh terhadap kehidupan sosial ekonomi masyarakat tidak jarang menimbulkan konflik atau sengketa lingkungan.

Dalam artikel ini, sengketa lingkungan hidup merupakan perselisihan antara dua pihak atau lebih yang timbul dari kegiatan yang berpotensi atau telah berdampak atau keduanya pada lingkungan hidup (Republik Indonesia 2009).

Selain itu, tidak terkait secara langsung dengan pencemaran atau perusakan lingkungan yang dilakukan oleh industri, masalah sosial ekonomi lainnya juga berkaitan dengan tingkat kesejahteraan masyarakat lokal. Kepedulian industri terhadap kesejahteraan masyarakat sekitar tidak terlepas dari kewajiban moral umum yang harus dilaksanakan untuk menciptakan hubungan yang harmonis dengan lingkungan masyarakat sekitar. Tanggung jawab sosial perusahaan bertujuan agar tercipta hubungan kemasyarakatan yang harmonis

\footnotetext{
*Penulis koresponden: widya.andharie@ecotas.org
} 
antara perusahaan dan masyarakat (Febrian dan Nugraha 2014).

Lebih lanjut dari sekedar persoalan tanggung jawab sosial perusahaan, diperlukan kajian sosial ekonomi sengketa lingkungan yang lebih komprehensif dan holistik. Artikel ini bertujuan untuk menjelaskan konsep pendekatan ekosistem sebagai bagian dari analisis sosial ekonomi dalam konflik lingkungan yang lebih komprehensif dan holistik.

\section{METODE PENELITIAN}

Artikel ini merupakan artikel konseptual dengan pendekatan adaptasi teori (theory adaptation). Seperti dikemukakan Jaakkola, adaptasi teori berusaha untuk mengubah teori yang ada dengan menggunakan teori lain. Teori lain digunakan sebagai alat untuk memberikan kerangka acuan alternatif untuk menyesuaikan atau memperluas ruang lingkup konseptualnya. Tinjauan pustaka (literature review) digunakan sebagai alat bantu (Jaakkola 2020).

\section{PEMBAHASAN}

\subsection{Pendekatan Ekosistem}

Menurut Buckles \& Rusnak dalam Dharmawan (2005:22), fungsi biofisik suatu ekosistem akan selalu menghadapi tantangan dan gangguan instabilitas, karena dalam setiap pemanfaatan sumber daya alam akan selalu terkait dengan empat dimensi yang penting, yaitu: (1) Sumberdaya alam ditemukan dan melekat pada bentang kawasan geografis yang saling berhubungan satu sama lain (interconnected space), sehingga suatu tindakan yang dilakukan oleh individu atau sekelompok orang pada satu titik akan menghasilkan dampak yang dirasakan hingga jauh di luar kawasan (off-site) dimana individu atau kelompok itu berada. (2) Sumberdaya alam terletak di dalam ruang sosial-politik dimana ditemukan kompleksitas hubungan sosial dan relasi kekuasaan yang seringkali tidak seimbang di antar pelaku sosio-ekonomi yang berinteraksi dan menjalankan pengaruhnya. Dalam kesatuan ruang geografis sumberdaya alam, keputusan-keputusan sosiopolitik yang dibuat suatu pihak akan mempengaruhi posisi pihak lain pada kawasan yang sama, baik secara langsung maupun tidak langsung. Hal ini terjadi karena mereka menyandarkan diri pada basis kehidupan (sumber daya alam) yang sama. (3) Sumber daya alam adalah material bernilai ekonomi yang selalu menghadapi persoalan kelangkaan akibat perubahan lingkungan, peningkatan permintaan dan ketimpangan distribusi. Perubahan lingkungan bisa terjadi karena eksploitasi lahan yang berlebihan (overexploitation), degradasi fungsi lahan dan air, pembukaan lahan yang dilakukan secara ekstensif dan perubahan pada teknologi dan penggunaan lahan. (4) Sumber daya alam tidak hanya dimaknai sebagai sumber daya material dimana setiap individu dan kelompok berkompetisi untuk mendapatkannya. Namun lebih dari itu, sumber daya alam juga berdimensi kultural dan bermakna sebagai identitas etnisitas, dan memiliki dimensi simbolik bagi komunitas tertentu.

Dengan adanya kompleksitas dan jalinan antardimensi yang kuat dalam pengelolaan sumber daya alam, maka permasalahan mememelihara derajat "kesehatan lingkungan" suatu ekosistem menjadi tidak sederhana. Secara biofisik, derajat "kesehatan lingkungan" suatu ekosistem akan dapat dipertahankan pada tingkat yang cukup baik jika ekosistem tersebut mampu menjamin ketersediaan air untuk berbagai aktivitas manusia, seperti industri, irigasi pertanian dan lain-lain. Secara sosiologis-ekonomis, "kesehatan lingkungan" suatu ekosistem disebut lestari jika eksistensinya dapat menopang tingkat kehidupan masyarakat hari ini dan generasi mendatang secara stabil. Secara sosio-politis, suatu ekosistem dengan derajat kesehatan lingkungan yang baik adalah yang tidak menimbulkan perpecahan pada masyarakat, utamanya pada golongan-golongan yang berbeda ideologi dan kepentingan.

Dengan demikian, integrasi manusia dalam sistem ekologi sangat mempengaruhi tingkat kelestarian sosio-ekologis sebuah ekosistem. Semakin besar tekanan penduduk, tekanan ekonomi dan tekanan sosio-politis terhadap suatu ekosistem, maka tekanan ekologis (yang ditunjukkan dengan daya dukung lingkungan yang semakin menurun) terjadi pada sistem ekologinya. Artinya, risiko kehancuran ekosistem akan menciptakan krisis ekologi yang berbanding lurus dengan tambahan jumlah aktivitas sosial-ekonomi, menajamnya perbedaan kepentingan sosialpolitis dan konflik sosial yang ditunjukkan oleh masyarakat (manusia) yang hidup di kawasan tersebut (Dharmawan 2005: 23) 


\subsection{Analisis Pemangku Kepentingan}

Pendekatan Analisis Pemangku Kepentingan (Stakeholder Analysis/SA) bermula dari ilmu bisnis dan manajemen, dimana ini terlihat dari terminologi asal kata "stakeholder" itu sendiri. Pendekatan SA merujuk pada sejumlah metode identifikasi dan deskripsi mengenai stakeholder berdasarkan atribut, keterkaitan dan kepentingan yang berkaitan dengan isu atau sumberdaya tertentu. Istilah SA sendiri bersifat lintas studi dengan menggunakan diantaranya: manajemen bisnis, penelitian partisipatif, ekologi, dan pengelolaan sumberdaya alam.

Menurut Grimble \& Quan dalam (Suharno 2005:6), SA adalah suatu pendekatan untuk memahami suatu sistem dengan cara mengidentifikasi aktor (-aktor) utama dalam suatu sistem dan mengakses kepentingan mereka dalam sistem tersebut. Definisi ini berguna untuk menyatakan SA sebagai "pendekatan pengelolaan sumberdaya alam yang mengakui keterbatasannya, bahwa pendekatan ini tidak bisa diharapkan untuk dapat menyelesaikan semua permasalahan atau menjamin representasi semua aktor" (Grimble \& Wellard dalam Ramirez (1999). SA menekankan pada perspektif aktor lokal dalam pertikaian kepentingan dan berbagai strategi alternatif yang bertujuan untuk mencapai kesetaraan dan berlangsungnya sistem pengelolaan sumberdaya alam.

Secara lebih spesifik, khususnya dalam isu-isu pengelolaan sumberdaya alam, Chevalier (2001:2-3) menyatakan bahwa SA digunakan untuk mengidentifikasi antara lain: (1) Stakeholder yang terlibat dalam kompetisi atau konflik terhadap sumberdaya alam. (2) Nilai dan pandangan stakeholder terhadap permasalahan pengelolaan sumberdaya alam dan strategi pengelolaan konflik. (3) Keadaan nyata atas sumberdaya, pengaruh, kewenangan atau kekuasaan yang dimiliki masing-masing stakeholder untuk dapat memikul berbagai inisiatif dalam pengelolaan sumberdaya alam. (4) Kepentingan dan tujuan stakeholder terkait dengan sistem pengelolaan sumberdaya alam.

(5) Jaringan dimana stakeholder berada serta pola dan konteks interaksi diantara mereka, akankah berkolaborasi atau bertikai.

Oleh karena itu, SA menjadi pendekatan yang mengkaji relasi kekuasaan antara individu dan kelompok serta kepentingan mereka terhadap suatu sumberdaya atau situasi. SA juga menggunakan metodologi partisipatif, dimana dalam praktiknya SA bertujuan untuk mempertinggi keterlibatan stakeholder dalam proses pengelolaan sumber daya alam, meskipun tidak semua pendekatan SA diterapkan melalui metode partisipatif.

Metode SA juga memiliki keunggulan sebagai paradigma yang fleksibel dan bersifat spesifik-konteks yang membantu dalam menentukan fokus terhadap permasalahan spesifik, aktor dan kemungkinan adanya perubahan. Paradigma ini akan sangat membantu dalam isu-isu manajemen sumber daya alam (natural resource managementNRM), dimana hubungan antar kelompok yang bersifat interdependen bergantung pada keberadaan sumber daya bersama seperti lahan, air dan hutan. Korporasi, petani skala-kecil, pedagang, agen pemerintah, kelompok konservasi dan etnis minoritas mungkin memiliki kepentingan yang bertentangan. Analisis multistakeholder akan lebih dibutuhkan jika sumber daya alam melintasi sistem administrasi, sosial, ekonomi dan politik yang berbeda dan beroperasi dalam tingkat mikro dan makro.

Terdapat banyak teknik yang dapat digunakan dalam pelaksanaan SA. Diskusi kelompok terfokus (focus group discussionFGD), wawancara dan workshop merupakan tiga pendekatan yang umum digunakan. Apapun pendekatan yang digunakan, setidaknya harus memenuhi tiga tahap esensial dalam SA, yaitu: 1) Mengidentifikasi stakeholder kunci dan kepentingan mereka dalam isu atau program; 2) Melakukan penilaian terhadap pengaruh, kepentingan, dan tingkat dampak isu/program pada setiap stakeholder; dan 3) Mengidentifikasi cara terbaik untuk melibatkan setiap stakeholder dalam penyelesaian permasalahan yang terkait dengan isu atau program (Golder dan Gawler 2005: 2).

Menurut Moeliono dkk. (2003:110-111), pada saat para pihak yang bersengketa bertemu untuk berunding atau pun dalam melakukan analisis para pemangku kepentingan (stakeholder analysis), biasanya mereka telah menentukan "posisinya", yakni apa yang akan mereka tuntut dari pihak "lawan" dan suatu sikap awal seberapa jauh mereka akan bersedia mendekati posisi (memenuhi tuntutan) pihak lawan dan secara bertahap mengurangi tuntutannya melalui proses tawar-menawar. Walaupun cara tersebut dapat menghasilkan 
Tabel 1. Perbedaan antara Posisi dan Kepentingan

\begin{tabular}{|c|c|c|}
\hline & Posisi & Kepentingan \\
\hline Pengertian & $\begin{array}{l}\text { Sikap awal dan tuntutan } \\
\text { terhadap lawan sengketa yang } \\
\text { sedapat mungkin harus } \\
\text { dipertahankan }\end{array}$ & $\begin{array}{l}\text { Keinginan, kebutuhan, harapan, } \\
\text { nilai yang ingin dipenuhi masing- } \\
\text { masih pihak }\end{array}$ \\
\hline Sifat & $\begin{array}{l}\text { Biasanya berupa suatu hal yang } \\
\text { konkrit, spesifik dan jangka } \\
\text { panjang }\end{array}$ & Abstrak, umum jangka panjang \\
\hline Asumsi & $\begin{array}{l}\text { Kemungkinan keluaran hanya } \\
\text { pemenuhan posisi salah satu } \\
\text { pihak atau suatu kompromi }\end{array}$ & $\begin{array}{l}\text { Kepentingan dapat dijadikan dasar } \\
\text { pengembangan berbagai alternatif } \\
\text { keluaran yang memenuhi } \\
\text { kepentingan para pihak secara } \\
\text { optimal. }\end{array}$ \\
\hline
\end{tabular}

Sumber: Moeliono dkk. (2003:110)

suatu kesepakatan, namun karena posisi pada umumnya saling berlawanan dan sulit dipadukan, mempertahankan posisi seringkali mengarah pada konfrontasi dan kesepakatan yang terjadi adalah suatu kompromi yang kurang menguntungkan, bahkan sering merugikan kedua belah pihak.

Untuk memungkinkan proses penyelesaian sengketa secara kooperatif ataupun dalam melakukan analisis pemangku kepentingan, masing-masing pihak harus mengenali kepentingan-kepentingan yang sebenarnya menjadi dasar posisi mereka dan membawa kepentingannya ke dalam proses penyelesaian sengketa. Hal ini dilakukan karena kepentingan lebih mudah dipadukan daripada posisi, dan jika perpaduan kepentingan itu dilakukan secara kreatif maka kesepakatan yang mungkin dicapai bukanlah sekedar kompromi, tetapi suatu penyelesaian yang secara optimal memenuhi kepentingan para pihak.

Agar dapat memisahkan posisi dan kepentingan, sebelumnya harus bisa memahami perbedaan antara kedua hal ini. Posisi adalah sikap awal dan tuntutan satu pihak terhadap pihak lainnya, sementara kepentingan adalah alasan-alasan mengapa, atau untuk apa, posisi itu diambil. Perbedaan antara keduanya dijelaskan dalam Tabel 1.

\subsection{Penghitungan Nilai Lingkungan}

Akhir-akhir ini istilah pembangunan berkelanjutan merupakan istilah yang banyak didengar, namun dalam kenyataannya tidak mudah untuk melaksanakannya karena pengurangan jumlah dan mutu sumber daya alam serta pencemaran lingkungan sulit dihindarkan.

Menurut Suparmoko (2006:1-2), lingkungan memiliki tiga fungsi utama, yaitu: (a) sebagai sumber bahan mentah yang dapat diproses di berbagai sektor ekonomi untuk memenuhi kebutuhan manusia; (b) sebagai tempat pengolah limbah alami, dan (c) sebagai pemberi jasa atau pelayanan langsung pada kehidupan manusia.

Berdasarkan pengamatan dan data lingkungan yang ada di Indonesia dan di banyak negara, terbukti bahwa ketiga fungsi utama lingkungan itu telah menyusut. Daya tampung lingkungan dalam menampung limbah telah menyusut drastis, sehingga pencemaran lingkungan tidak dapat dihindari. Alam sebenarnya memiliki daya tampung limbah yang tak terhingga, namun karena limbah produksi dan konsumsi yang dibuang ke alam telah jauh melebihi daya tampung lingkungan, maka limbah tersebut menjadi pencemar dan pencemar inilah yang mengganggu kehidupan dan kesehatan manusia. Karena itu, tanpa pemberian nilai terhadap lingkungan, baik yang berupa manfaat maupun berupa kerugian atau kerusakan, maka usaha-usaha pengelolaan lingkungan sulit 
untuk dapat dikatakan berjalan dengan efektif atau tidak.

Secara sederhana, terdapat beberapa langkah yang harus ditempuh dalam melakukan valuasi ekonomi terhadap sumber daya alam dan lingkungan, yaitu: (a) Mengidentifikasi fungsi lingkungan dan dampak suatu kegiatan; (b) Mengkuantifikasi besarnya dampak tersebut; (c)Menyatakan dampak kuantifikasi tersebut dalam nilai uang (harga); dan (d) Membuat analisis ekonomi.

\section{PENUTUP}

Analisis dan pemetaan pemangku kepentingan dengan pendekatan ekosistem serta penghitungan nilai lingkungan merupakan salah satu bagian penting dalam pemetaan konflik aspek sosial ekonomi untuk mendapatkan gambaran yang utuh sehingga dapat membantu upaya penyelesaian konflik lingkungan dengan memperhatikan konteks lokal.

Aspek sosial ekonomi masyarakat dalam kategori tanggung jawab sosial perusahaan seharusnya dilembagakan dalam hubungan yang langgeng berupa kemitraan antara industri dan masyarakat yang hakiki.

\section{DAFTAR PUSTAKA}

Chevalier, Jacques M. 2001. "Stakeholder analysis and natural resource management." Carleton University. http://www1.worldbank.org/publicsect or/politicaleconomy/November3Semin ar/Stakehlder\%20Readings/SA-

Chevalier.pdf.

Dharmawan, A.H. 2005. Sistem tatapemerintahan sumberdaya alam dan lingkungan di daerah aliran sungai Citanduy: Perspektif politik ekologi. Bogor: Project Working Paper Series (09), Environmental Partnership System. PSP-IPB bekerja sama dengan Partnership for Governance Reform in Indonesia UNDP, Bogor.

Febrian, Mr, dan Adrian Nugraha. 2014. "Kajian Socio Legal Tanggung Jawab Sosial Lingkungan Hidup Perusahaan Berdasarkan Persepsi Masyarakat." Mimbar Hukum 26 (3). https://doi.org/10.22146/jmh.16033.
Golder, Bronwen, dan Meg Gawler. 2005. Cross-Cutting Tool Stakeholder Analysis. Gland: WWF.

Jaakkola, Elina. 2020. "Designing conceptual articles: four approaches." $A M S$ Review $\quad 10 \quad$ (1): 18-26. https://doi.org/10.1007/s13162-02000161-0.

Moeliono, I., L. Fisher, dan S. Wodicka. 2003. Buku acuan metodologi pengelolaan sengketa sumberdaya alam: Memadukan kepentingan memenangkan kehidupan. Bandung: Studio Driya Media bekerjasama dengan World Neighbors, Konsorsium Pengembangan Masyarakat Nusa Tenggara dan The Ford Foundation.

Ramirez, R. 1999. "Stakeholder analysis and conflict management." Dalam Cultivating Peace: Conflict and Collaboration in Natural Resource Management, disunting oleh Daniel Buckles. Washington: International Development Research Center dan World Bank Institute.

Republik Indonesia. 2009. Undang-Undang Nomor 32 Tahun 2009 tentang Perlindungan dan Pengelolaan Lingkungan Hidup. Lembaran Negara Tahun 2009 Nomor 140, Tambahan Lembaran Negara Nomor 5059.

Suharno. 2005. Dewan Sumberdaya Air: Analisis Kelembagaan dan Organisasional. Bogor: Pusat Studi Pembangunan-IPB dan UNDP.

Suparmoko, M. 2006. Panduan dan analisis valuasi ekonomi. Yogyakarta: Badan Penerbit Fakultas Ekonomi UGM. 